\title{
DEVELOPMENT OF REMOTE JOBS AS A FACTOR TO INCREASE LABOR EFFICIENCY
}

\author{
Eka Maghlaperidze \\ Ivane Javakhishvili Tbilisi State University, Georgia \\ Natalia Kharadze \\ Ivane Javakhishvili Tbilisi State University, Georgia \\ Halyna Kuspliak \\ Odesa Regional Institute for Public Administration of the National Academy for Public \\ Administration under the President of Ukraine
}

\begin{abstract}
The purpose of the study was to assess the effectiveness of remote work and the determining factors of its development. Based on survey data taken from 528 employees of insurance companies in Georgia over the period of December 2020 - January 2021, the features of remote work have been determined. The factors influencing the effectiveness of remote work were substantiated by Principal Component Analysis (PCA). Structural modeling confirmed the qualitative nature of the influence of the intensity of remote work on the level of its effectiveness, taking into account the factors of its effectiveness. The regularities and priority of the impact of the characteristics of the effectiveness of remote work depending on its intensity have been substantiated. The optimal volume of remote work has been determined empirically with its maximum efficiency ensured in terms of increasing the productivity and satisfaction of employees of insurance companies.
\end{abstract}

Keywords: remote employment, remote work, employees, business, efficiency, Georgia, labor intensity, labor productivity.

DOI: http://dx.doi.org/10.15549/jeecar.v8i3.669

\section{INTRODUCTION}

The prolonged spread of the COVID-19 pandemic has created significant vulnerabilities for businesses and economies worldwide. The harsh forced restrictions imposed by the country governments to delay the pandemic significantly reduced hiring across the board. And while millions of employees were transferred to remote work, some lost their jobs altogether. By the beginning of 2021, around 255 million jobs 
were lost, about four times more than during the 2009 global financial crisis (International Labor Organization, 2021). During the pandemic, however, some specific trends that existed before COVID-19 accelerated (McKinsey, 2020). One of the main ones is an increase in telecommuting/hybrid employment. The prevalence of telecommuting - performing work tasks from home as a "back office" - was low until COVID-19 led to widespread lockdowns. But even after remote working decreased after coronavirus restrictions were reduced, its share of the workforce remains much higher compared to pre-pandemic levels (Berg, Bonnet \& Soares, 2020). What began as a forced and temporary measure during the pandemic now has every chance of becoming a long-term solution for many companies. In the context of the democratization of opportunities for teleworking, it is noted that its effects include:

- Increasing labor productivity and job satisfaction;

- Improving communication between management and employees, and the overall business climate in the company;

- Increasing the interest of employees in the performance of their duties;

- Increasing the mobility of talented employees, and for business, there is an opportunity for the broadest access to various skills and talents previously unavailable (Microsoft, 2020).

The increasing spread of remote work does not entail only positive economic effects, however, but includes some destructive factors as well, the main of which are:

- Reduction in professional communication, which threatens the development of innovations, investments in $R \& D$, and economic growth due to the loss of agglomeration effects;

- Increasing the remoteness of managers, which reduces their authority, and, consequently, reduces the effectiveness of human resource management;

- Increasing the risk of non-confidentiality of information or possible violations of labor safety;

- Increasing stress among employees due to social isolation, especially among employees who have poor organizational skills;
- Can affect the career prospects and priorities of employees negatively, etc.

As the results of scientific research (Schall, 2019; Gajendran \& Harrison, 2007; Nuwer, 2016; Megits, Neskorodieva \& Schuster, 2020) proved, the development of remote work has an ambiguous effect on the economy and the efficiency of a business. The relationship between the level of distribution of distance employment and GDP has the shape of an inverted "U"; that is, up to a certain point, an increase in the share of distance employment contributes to the development of the economy. It has a positive effect on the labor market, but it is a destructive factor after a certain point (Schall, 2019; Gajendran \& Harrison, 2007).

The goal of any business is to maximize profits while minimizing costs. The tasks of optimization and increasing economic efficiency have always faced entrepreneurs, but during the pandemic, these tasks became especially urgent. During the pandemic, online employees worked on average almost $10 \%$ more and communicated - via online meetings - 13\% more frequently. But at the same time, taking into account the influence of numerous factors, not everyone was able to maintain productivity (DeFilippis et al., 2020). What the pandemic revealed is that it is essential to find the fastest way to optimize the combination of remote work and office work to maintain and increase productivity. This study, then, aims to identify the factors of the effectiveness of remote work that characterize employees' cognitive and professional qualities and empirically substantiate the optimal volume (intensity) of remote work to maximize efficacy using an example of Georgian insurance companies.

\section{LITERATURE REVIEW}

Investigations of the impact of remote work as a flexible form of work performance began as early as the 1970s. The term "telecommuting" was first coined by Jack Nilles (1975) in the 1970s when he was working remotely as an engineer on NASA's communications systems and referred to his work as telecommuting. He later defined telecommuting as working outside of a standard workplace through telecommunications and computer-based technology (Nilles, 1994). Belanger and Collins (1998), who coined the term 
'distributed work', also researched flexible workplace and environmental issues. According to their definition, distributed work is an agreement that allows employees to share workrelated tasks away from the central location of the business or its physical organizational location. The most well-known type of distributed work is telecommuting. In addition, this type of work arrangement is recognized as 'telework' or 'remote work' (Gajendran \& Harrison, 2007).

A remote work agreement between the employer and the employee can be both full and part-time. According to (International Labor Organization, 2020), individuals who work remotely under a full-time contract agreement do all the work away from the office, with very little face-to-face interaction (or no interaction at all) with their supervisor and co-workers. Parttime remote work is a type of agreement in which employees perform the functions assigned to them only a few days a week, and part of the work is completed from the employer's office. The number of part-time telecommuters is increasing day by day. The popularity and recognition of this type of agreement simultaneously provide the best way to reduce costs and maintain a balance between work and personal life (International Labour Organization, 2020). According to the 2020 State of Remote Work survey, which was conducted worldwide and surveyed 3,500 remote workers, $57 \%$ of respondents are full-time remote workers, and $45 \%$ of employees work part-time, with $27 \%$ working more than half of their time, and $18 \%$ working less than half of their time remotely (Buffer and AngelList, 2020).

The relationship between remote work and job satisfaction derives from the assumption that remote work gives workers more flexibility and autonomy in their work performance while allowing them to meet both work and personal (personal and family) needs (Schall, 2019). Locke defined job satisfaction as a pleasurable or positive emotional state resulting from the appraisal of one's job or job experiences (Villani et al., 2021). In the context of job satisfaction, telecommuting intensity is of enormous importance. Different assessments have been reported about the impact of remote work on job satisfaction. For example, some researchers have argued that a linear relationship between job satisfaction and remote work exists since people who work remotely more are more satisfied with their jobs (Irawanto, Novianti \& Roz, 2021).

On the other hand, some researchers believe that the more time employees spend working remotely, the less satisfied they are with their jobs (Wang et al., 2021; Vasiljeva et al., 2020). According to studies by Schall (2019) and Nuwer (2016), as the intensity of remote work increases, so does job satisfaction, but only to a certain point. Based on recent studies (Irawanto, Novianti \& Roz, 2021), the higher the intensity of remote work, the more satisfied employees are. In the group of people who spend only $1 / 4$ of their time working remotely, $82 \%$ of the respondents said they want to work remotely more often (Buffer and AngelList, 2020). A joint study by Owl Labs and Global Workplace Analytics found that $71 \%$ of people working remotely are happy with their job, while $55 \%$ of people working in the office are satisfied with their job. Remote workers say they're comfortable in their jobs 29\% more than on-site workers (Owl Labs, Global Workplace Analytics, 2019).

The impact of telecommuting on labor capacity is still a controversial issue (Schall, 2019, Nuwer, 2016). The development of remote employment generates several polemical judgments. Highly skilled workers face a choice: reap the benefits of interactions in the office but bear the cost of commuting to work; or save on transportation but not receive the benefit of the effects of agglomeration and incur additional housing costs since part of the living space must be used as an office (Wang et al., 2021). Businesses are faced with a choice between reduced productivity due to reduced agglomeration effects and reduced office costs. According to recent scientific research, the proportion of distance employment that maximizes labor productivity with a remote job was determined to be within $20 \%$ to $40 \%$, equivalent to $1-2$ working days in a 5-day working week (Gajendran \& Harrison, 2007). Until the inflection point is discovered, though, teleworking increases the productivity of both skilled and unskilled workers without significantly altering the balance of demand for office and residential premises and at the same time increasing the potential for using information and 
telecommunication technologies (Nuwer, 2016). But given that remote work increases employee satisfaction, its effectiveness affects workforce tension and the amount of work spent by the employee per unit of time (European Parliament, 2021). There is an increase in internal human resources for the labor expended (Irawanto, Novianti \& Roz, 2021).

We formulated the following hypotheses of scientific research within the framework of our study:

Hypothesis 1 (H1): The effectiveness of remote work is defined as a cognitive category because it is characterized by the expenditure of labor, emotional, mental, and other resources;

Hypothesis 2 (H2): Intensity is characterized by a directly proportional relationship with the effectiveness of remote work;

Hypothesis 3 (H3): An increase in the share of remote work is characterized by a differentiated impact on its effectiveness: it has first a positive and then a negative impact.

\section{METHODOLOGY}

The object of our research is insurance companies operating in Georgia. Using an anonymous survey method (carried out during December 2020 - January 2021), 528 employees of the mentioned organizations participated in the study. Participation in the survey was voluntary. The structure of respondents: $2.65 \%$ Senior Managers, 9.47\% Middle Managers, and $87.88 \%$ Specialists, which corresponds to the structure of the total population provided by the Insurance State Supervision Service of Georgia (2021). Employees of insurance companies located in all regions of Georgia took part in the survey. Sufficient population size at a significance level of 0.05 (Taherdoost, 2017), broad region representation, different sizes, and scales of activity of insurance companies, of which the respondents are representatives, testify to the representativeness of the survey results.

The survey was carried out remotely via emails using Google Forms (2021). The questionnaire survey consisted of 2 sections. The first section contained: 1) general information about the respondents (gender, age of the respondent, position in the organization, territorial location of the organization); and 2) information on the distribution of working time in the context of remote work and office work (intensity of remote work).

The intensity of remote work (RW) was determined based on the score for the questionnaire:

1) "How often do you work remotely now?" (RW1).

2) "How has the ratio of telecommuting and office work changed during the pandemic?" (RW2).

The second section was developed to learn the respondents' attitudes towards remote work, studying the preferred form of work, its advantages and disadvantages, and assessing its effectiveness and the factors that affect it. These questions were assessed using a 5-point Likert Scale. The primary indicator for assessing labor efficiency is the indicator of productivity (Langemeier, 2018). The complexity of its use lies in the fact that it does not allow setting the individual labor productivity in the organization. In this regard, the following questionnaire questions were used to assess the effectiveness of remote work: "Do you work more productively remotely than in the office?" $\left(\mathrm{LP}_{1}\right)$, "By an overall assessment, are you satisfied with your current job?" $\left(\mathrm{LP}_{\mathrm{c}}\right)$. The higher score on the indicators corresponds to the higher efficiency of remote work. These indicators reflect current efficiency $\left(\mathrm{LP}_{\mathrm{l}}\right)$ and prospective efficiency $\left(\mathrm{LP}_{\mathrm{c}}\right)$, which determines the desire to work, depending on comfort and the safety of the working conditions.

Among the possible factors affecting the effectiveness of remote work, the following twenty were assessed:

- The ability to combine childcare with work (indicator F1);

- The ability to connect work and personal life (F2);

The presence of support in professional implementation from the family (F3) (Pirtskhalaishvili, Paresashvili \& Kulinich, 2021);

- Responsibility (F4);

- Dedication (F5);

- Career aspirations (F6);

- Perseverance (F7);

- Ability to abstract (F8) (Wang et al., 2021); 
- Effective time management skills (Miglioretti et al., 2021);

- The competence of the employee (F10);

- the need for consultation or assistance from colleagues (F11) (Van Zoonen et al., 2021);

Mental characteristics of respondents according to the typology of Hofstede cultures:

- Individualism (F12);

- Masculinity (F13);

- Uncertainty avoidance (F14);

- Indulgence (F15) (Hofstede Insights, 2021);

- The presence of a comfortable workplace for remote work (F16) (Miglioretti et al., 2021);

- The presence of converged telephony (when employees, working remotely can transfer calls to colleagues) (F17);

- Technical readiness for video conferencing and online collaboration (F18);

- The presence of skills and abilities of the respondent (F19);

- As well as colleagues to work remotely (F20) (Van Zoonen et al., 2021).

The study used PCA to determine the structure of factors affecting the effectiveness of remote work and calculate the values of the factors, and structural equations in the Statistica 12.0 program to simulate the influence of factors, as well as the effect of the intensity of remote work on its effectiveness. The values of the factors were calculated using the following formula (Menke, 2018):

$$
F_{j}=\sum_{i=1}^{n} W_{j i} \times V_{i}
$$

where $F_{j}$ - a value of the $j$ th factor;

$W_{j i}$ - loads of the $j$ th factor on the $i$-th variable or load factor;

$V_{i}$ - the normalized value of the $i$-th variable, calculated based on the respondent's scores;

$n-$ a number of variables.

The endogenous variable of the model was the latent variable LP, obtained using PCA, which characterizes the effectiveness of remote work and combines $\mathrm{LP}_{1}$, and $\mathrm{LP}_{\mathrm{c}}$. Exogenous variables formed the main components representing the intensity of remote work (RW) and factors influencing the effectiveness of remote work, which combine (F1-F18). The values of the main components (factors) were based on normalized scores for the questionnaire using the Statistica 12.0 program. The number of observations corresponds to the number of respondents $(\mathrm{N}=528)$.

The Mann-Whitney test in the Statistica 12.0 program and the Chow test in the EViews 10 program was used as auxiliary data processing methods.

\section{RESULTS}

We asked what part of the employees' working time is devoted to remote work. It turned out that $63.8 \%$ of respondents work entirely remotely, and $26 \%$ of respondents work primarily remotely. The findings are drawn from the reality of the pandemic, which has forced changes in the way people work. Consequently, companies are forced to transfer employees to a remote mode of work.

Regarding the intensity of remote work, $48.3 \%$ of the respondents stated that they would like to work remotely less often, indicating that it is less desirable since most respondents work remotely. In contrast, only $3.8 \%$ of the respondents would like to work remotely more often, while $42.2 \%$ of respondents are satisfied with the working time devoted to remote working.

In the context of job satisfaction, according to our results, people who work remotely for 3 or 4 days a week are most satisfied with their job (88\% / 81\%), while the most dissatisfied are the ones who work remotely 5 days a week (15.9\%), $50.5 \%$ of full-time remote workers are partly satisfied.

To assess the impact of remote work intensity on respondents' views, the respondents were asked to identify the most significant disadvantages and advantages of working remotely. For full-time (5 days) remote workers, the most considerable drawback of remote work was the difficulty of keeping work and home lives separate (29.1\%), followed by overwork stress and fatigue (26.1\%), and then the reduction in peer relations $(25.2 \%)$. The most significant disadvantage for part-time remote workers is reducing relations with colleagues (35\%), various external distractions such as noises from family members, technical malfunction (33.6\%), and the difficulty of separating work and home lives (24.1\%). 
The most significant advantage for full-time remote workers is the ability to work from anywhere $(24.3 \%)$, followed by the time savings (22.8\%) and cost reduction (22.6\%) of commuting. For part-time remote workers, a flexible work schedule (44.5\%), as well as commuting time saving (24.1\%) and a better work-life balance (12.4\%) are preferred.

According to the results, the standard variable for both groups in the top three advantages of remote working is the time saving from commuting, which allows us to make an important conclusion: the commuting time saving is one of the most important factors among the advantages of remote work. Instead, people spend their free time according to their interests.

Regarding the intensity of remote working, we also studied the work-family conflict - how well the remote employees can balance work and personal life. Nowadays, organizations are becoming more and more interested and involved in this issue. They realize the great importance of work-life balance and bring some strategic initiatives to improve it, either formally or informally (Hossen, Begum, \& Zhixia, 2018). As a result of our research, it was found out that most part-time remote workers are better able to maintain a balance between work and personal life while working remotely (70.8\%), and fulltime remote workers mostly reject this statement (64.1\%). This allows us to draw an important conclusion: full-time remote workers find it challenging to balance personal and work responsibilities effectively since they are constantly working from home, experiencing the blurring of boundaries between paid work and personal life, and facing work-family conflict and professional isolation.

Opinions on reducing the chances of career advancement differ among the groups of respondents according to the intensity of working remotely. For example, most full-time remote workers - 68.5\% - think that their chances of career advancement while working remotely are reduced because their manager rarely sees them. In contrast, part-time employees believe the opposite. The explanation for these results lies in the fact that part-time remote workers do not feel professionally isolated. They go to the office once a week (at least) and meet with a supervisor, so they do not think working remotely may reduce their chances of career advancement.

We selected part-time remote workers $(1,2,3$, or 4 days a week) (137 respondents) and used frequency tables to see if part-time remote working caused greater productivity and job satisfaction in them. According to the cumulative percentage, the share of respondents who "strongly agree" or "agree" with the question "Do you work more productively remotely than in the office?" is $77 \%$; the share of those who "disagree" and "strongly disagree" is $14 \%$. Therefore, we can say that partial remote work leads to more self-rated productivity compared to the workplace. Also, as the results of the survey show, for the question "By an overall assessment, how satisfied are you with your current job?", $80 \%$ of the part-time remote workers are satisfied with their current job, and $19 \%$ are on average comfortable, for a cumulative percentage of $99 \%$ being at least comfortable with their current job. Only $1 \%$ are unequivocally dissatisfied.

Table 1: Statistical parameters of the relationship between effectiveness of remote work and the desire to work remotely

\begin{tabular}{|l|c|c|}
\hline \multicolumn{1}{|c|}{ Parameters } & LP $_{1}$ & LP $_{\mathbf{c}}$ \\
\hline Mann-Whitney U & 7156.500 & 6921.000 \\
\hline Wilcoxon W & 12616.500 & 12381.000 \\
\hline Z & -5.174 & -5.249 \\
\hline Asymp. Sig. (2-tailed) & 0.000 & 0.000 \\
\hline \multicolumn{2}{|c|}{ Grouping Variable: “Other things being equal, would you change a job for remote work possible?” } \\
\hline
\end{tabular}

Source: Authors' finding

We also used the Mann-Whitney test to determine the existence of a relationship of the 
variables $\mathrm{LP}_{1}$ and $\mathrm{LP}_{\mathrm{c}}$. As a grouping variable, we used the score for the question: "Other things being equal, would you change a job for remote work possible?" (Table 1 ).

As a result of the test analysis, we see a statistically significant relationship between $\mathrm{LP}_{1}$, $\mathrm{LPc}$, and the grouping variable at the level of 0.01 . This indicates that part-time remote work leads to greater self-rated productivity and job satisfaction, and such employees are less willing to change their jobs.

The received assessments of the respondents indicate that the effectiveness of remote work depends on its intensity. To formalize this dependence, PCA was carried out and suggested structural equations.

Based on the results of PCA application, the structure of factors influencing the effectiveness of remote work was determined (Table 2). The number of factors is determined according to the Kaiser criterion, according to which factors whose eigenvalues are not lower than 1.0 are considered statistically significant. The belonging of indicators to factors is determined based on the load factor between them. Load factors not lower than 0.7 | were used as significant ones.

Table 2: Factors affecting the effectiveness of remote work

\begin{tabular}{|l|c|c|c|}
\hline \multicolumn{1}{|c|}{ Factors } & Indicators & $\begin{array}{c}\text { The } \\
\text { eigenvalue }\end{array}$ & $\begin{array}{c}\text { Factor dispersion, } \\
\%\end{array}$ \\
\hline $\begin{array}{l}\text { Personnel professional } \\
\text { competence factor }\left(\mathrm{F}_{\mathrm{COM}}\right)\end{array}$ & $\begin{array}{c}\text { F10, F11, F19, } \\
\text { F20 }\end{array}$ & 3.43 & 25.17 \\
\hline Self-organization factor $\left(\mathrm{F}_{\mathrm{ORG}}\right)$ & F4, F5, F7, F9 & 2.67 & 19.59 \\
\hline Work-family balance factor $\left(\mathrm{F}_{\mathrm{BAL}}\right)$ & $\mathrm{F} 1, \mathrm{~F} 2, \mathrm{~F} 3, \mathrm{~F} 8$ & 2.23 & 16.36 \\
\hline $\begin{array}{l}\text { The factor of mental } \\
\text { characteristics of staff }\left(\mathrm{F}_{\mathrm{MEN}}\right)\end{array}$ & $\begin{array}{c}\text { F12, F13, F14, } \\
\text { F15 }\end{array}$ & 2.08 & 15.26 \\
\hline $\begin{array}{l}\text { The material and technical } \\
\text { support factor }\left(\mathrm{F}_{\mathrm{MAT}}\right)\end{array}$ & F16, F17, F18 & 1.19 & 8.73 \\
\hline Total Variance, \% & - & - & 85.11 \\
\hline
\end{tabular}

Source: Authors' finding

The selected factors do not include an indicator of career ambitions (F6). Loads Factors between this indicator and the selected factors do not exceed $|0.32|$. Between the F6 indicator and the remote work efficiency indicators $\left(\mathrm{LP}_{\mathrm{l}}, \mathrm{LP}_{\mathrm{c}}\right)$, the values of the paired correlation coefficients do not exceed $|0.28|$, which indicates that there is no significant effect of this factor on the effectiveness of remote work. In this regard, the F6 indicator can be neglected in further calculations.

The personnel professional competence factor characterizes the presence of professional knowledge and skills necessary to independently perform work without consulting employees, which in remote work conditions is more limited than working in an office. This factor also includes the skills and abilities of the respondent and colleagues to work remotely, working and transferring data through online applications.
The self-organization factor determines the effectiveness of remote work through the ability of respondents to organize their working time and focus on work. According to the survey results described above, separating work and home life is one of the main disadvantages of teleworking.

The work-family balance factor assesses the possibilities of effective organization of remote work through combining childcare with work and personal life, the ability to abstract, and the presence of support in career growth from the family.

The factor of mental characteristics characterizes 1) a tendency to individualism, which allows you to feel comfortable in a remote work environment; 2) the priority of focusing on achieving goals, compared with an orientation on the value system, which avoids bias in favor of the family when determining the balance 
between work and personal life; 3 ) a positive attitude towards uncertainty, which is changing working conditions - the transition from office work to remote work; and 4) the degree to which respondents try to control their desires and impulses, which is the basis of self-organization.

The material and technical support factors characterize the objective basis required for remote work. This is the presence of a comfortable workplace for remote work; the presence of converged telephony, when employees, working remotely, can transfer calls to colleagues; and technical readiness for video conferencing and online collaboration.

The adequacy of the PCA is evidenced by the sufficiency of the sample (the number of observations is 26.4 times the number of variables) and a cumulative percentage of the variance of $85.11 \%$.

A model for assessing the effectiveness of remote work, considering its intensity and influencing factors, built using the method of the structural equation is shown in Fig. 1, Table 3.

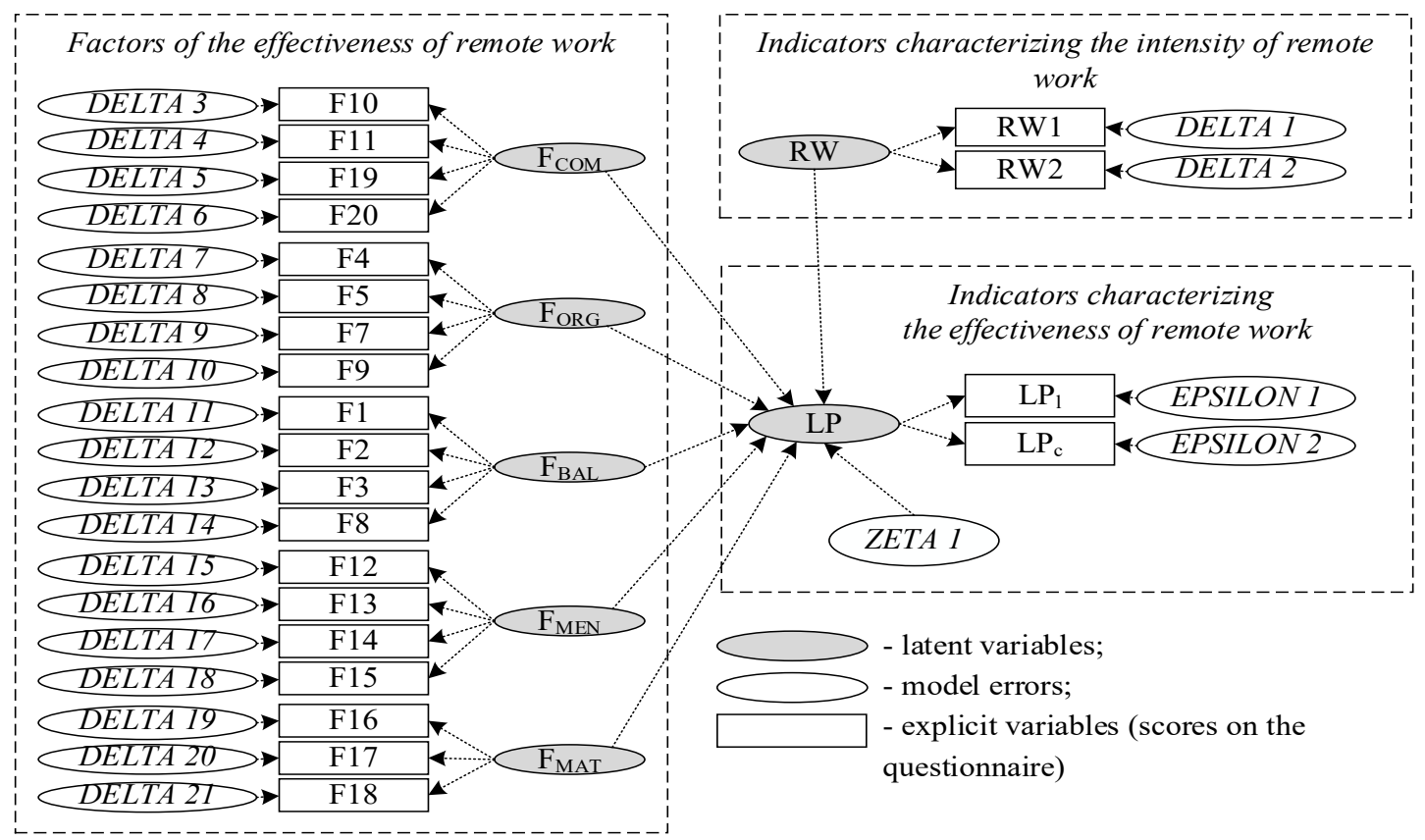

Figure 1: Components of the model for assessing the effectiveness of remote work Source: Authors' finding

The Chow test was used to check structural breaks, such as the intensity of remote work on its effectiveness. The presence of structural breaks was rejected with a probability of 0.03 , which is statistically insignificant, indicating structural intervals in the model. In this regard, two models have been built that reflect the influence of the intensity of remote work on its efficiency: 1st - for respondents who work remotely 4-5 days a week (formula 1 ), 2nd - for respondents who work partially remotely (1-3 days a week) (Formula 2, Table 3 ).

The criteria confirming the adequacy of the constructed models are the values of ICSF Criterion and ICS Criterion, which for model (1) were $1.3 \times 10^{-7}$ and $4.1 \times 10^{-6}$, respectively and for model (2) $-6.1 \times 10^{-7}$ and $9.2 \times 10^{-5}$; Maximum Residual Cosine values are $5.1 \times 10^{-5}$ for model (1) and $8.0 \times 10^{-4}$ for model (2). The values of these criteria tend to be 0 , which indicates the adequacy of the models. The statistical significance of the model variables is confirmed by T-Statistic, according to which the empirical values exceed the critical ones at a significance level of 0.05 . The values of elasticity indicators for models (1) - (2) characterize the percentage change in the efficiency of remote work (LP) with an increase in the value of an individual factor by $1 \%$ relative to the average for the sample population. 
Table 3: The model for assessing the effectiveness of remote work

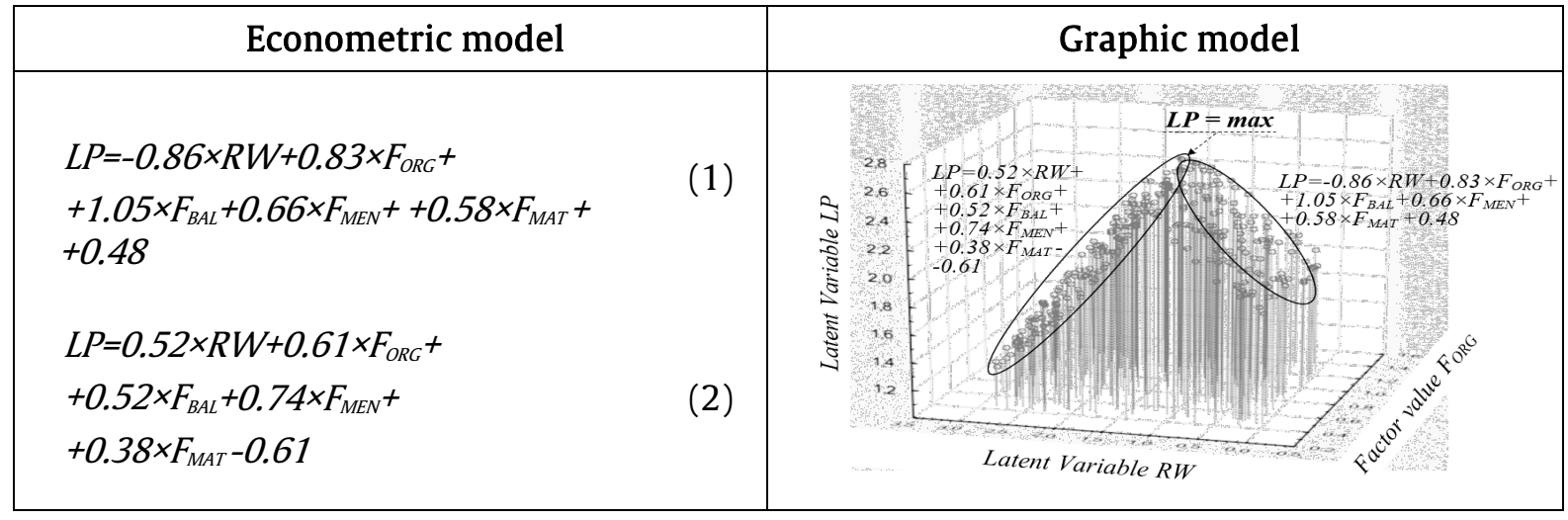

Source: Authors' finding

The increase in the intensity of remote work, assessed through RW, has a positive effect on the efficiency of remote work of respondents who work remotely no more than 3 days a week, and a negative one for respondents who work remotely 4-5 days a week.

\section{DISCUSSION AND CONCLUSION}

The study results allow us to develop an approach that allows one to quantitatively and reliably assess the effectiveness of distance employment using the example of insurance companies in Georgia, taking into account many factors that reflect the cognitive characteristics of workers and their level of professional qualifications and competence. Hypothesis 1 is supported within the framework of the study; the effectiveness of distance employment is primarily determined by the cognitive characteristics of employees, regardless of the level of labor intensity. For respondents who work remotely for 4-5 days a week, the most significant factors determining the effectiveness of remote work are the factor of balance between work and family (elasticity value $0.52 \%$ ), selforganization factor (elasticity value $0.46 \%$ ), mental features (the value of the elasticity index is $0.35 \%$ ); and the factor of material and technical support (the value of the elasticity index is $0.34 \%)$.

For respondents working remotely 1-3 days a week (Formula 2), the composition of priority factors is identical. The models differ in the significance of these factors. For this group of respondents, the most significant factor is mental characteristics (the value of the elasticity index is $0.33 \%$ ). Less significant factors are indicated in decreasing order of importance: self-organization factor (elasticity value $0.28 \%$ ); work-family balance factor (elasticity value $0.22 \%$ ); and material and technical support factor (elasticity value $0.18 \%$ ).

The positive influence of these factors on the effectiveness of remote work determines the need to provide employees with the necessary material and technical base for remote work, as well as to conduct appropriate training in the organization aimed at developing selforganization skills and the ability to maintain a balance between work and family, which will have a positive effect on the effectiveness of remote work.

The professional competencies factor does not have a statistically significant (at a significance level of 0.05) impact on the effectiveness of remote work. This can be explained by the fact that the respondents who took part in the survey have a sufficient level of professional competencies necessary for the high-quality performance of their official duties in an office environment and under the condition of remote work.

Hypotheses 2 and 3 about the differentiated nature of the influence of the intensity of remote work on its effectiveness, widely discussed in scientific works (Schall, 2019; Gajendran \& Harrison, 2007; Nuwer, 2016) are confirmed within the framework of this study. The intensity of remote work plays an essential role in the respondents' sense of job satisfaction: part-time 
remote work leads to more pleasure than fulltime remote work. The intensity of remote work has an important impact on balancing work and personal life. Part-time remote workers are better able to maintain a work-life balance than full-time remote workers. But at the same time, the positive impact of the development of remote work has a limited effect on its effectiveness. Therefore, the approach proposed in our study has made it possible to determine the optimal level of intensity (number of days) of the remote form of employment. The optimal number is the number of remote workdays at which the maximum efficiency of remote work is achieved. With a given level of professional competence of employees, the current status of self-organization, a balance between work and family, mental characteristics inherent in the country, and material and technical support, remote work is most effective for 3 days a week, after which, with an increase in intensity, efficiency decreases. The minimum efficiency is observed at the maximum value of the RW indicator, which corresponds to 5 days of remote work.

The results of this study were obtained using a limited sample of respondents from one country (Georgia) and one economic specialization (insurance). This limits the possibility of extending them to developing remote work in other countries and other spheres of economic activity. But it forms before us the tasks of further research of the features of the modification of forms of employment in various sectors of an economy depending on the level of its development.

Also, our study's limiting point is that when constructing models for assessing the effectiveness of remote work, we used latent variables, which have normalized values. These variables have no economic interpretation and by themselves only allow us to identify patterns in the influence of factors on the effectiveness of remote work. At the same time, it is not possible to determine the number of days of remote work at which its efficiency is maximized. This shortcoming in this study is leveled by comparing the values of the factors with the scores for the questionnaire questions for the sample used. However, to apply the proposed approach to other industries and countries, it will be necessary to recalculate the values of the factors and re-simulate them.

\section{REFERENCES}

Belanger, F., \& Collins, R. W. (1998). Distributed work arrangements: A research framework. Information Society, 14, 137-152. https://doi.org/10.1080/019722498128935

Berg, J., Bonnet, F., \& Soares, S. (2020). Working from home: Estimating the worldwide potential. https://voxeu.org/article/workinghome-estimating-worldwide-potential

Buffer and AngelList. (2020). The 2020 State of Remote Work. https://lp.buffer.com/stateof-remote-work-2020

DeFilippis, E., Impink, S.M., Singell, M., Polzer, J.T., \& Sadun, R. (2020). Collaborating During Coronavirus: The Impact of COVID-19 on the Nature of Work. https://www.nber.org/papers/w27612

European Parliament. (2021). The impact of teleworking and digital work on workers and society. Luxembourg.

Gajendran, R. S., \& Harrison, D. A. (2007). The good, the bad, and the unknown about telecommuting: Meta-analysis of psychological mediators and individual consequences. Journal of Applied Psychology, 92, 1524-1541. https://doi.org/10.1037/00219010.92.6.1524

Google Forms. (2021). Evaluating the Effectiveness of Remote Work https://docs.google.com/forms/d/e/1FAIpQL SeuyT1ldwGkVvRWMvR1S5EjzyiHiOrBLfRHJ QLZo-gj0JRreg/viewform

Hofstede Insights. (2021). Country Comparison. https://www.hofstedeinsights.com/country-comparison/

Hossen, M. M., Begum, M., \& Zhixia, C. (2018). Present Status of Organizational Work-Life Balance Practices in Bangladesh: Employees Expectation and Organizational Arrangements. Journal of Eastern European and Central Asian Research (JEECAR), 5(1). https://doi.org/10.15549/jeecar.v5i1.199

Insurance State Supervision Service of Georgia. (2021). https://www.fms.gov.ge/eng/page/reports 
International Labour Organization. (2020). Teleworking during the COVID-19 pandemic and beyond. Geneva

International Labour Organization. (2021). COVID-19 and the world of work. https://www.ilo.org/global/topics/coronavir us/lang--en/index.htm.

Irawanto, D.W., Novianti, K.R., \& Roz, K. (2021). Work from Home: Measuring Satisfaction between Work-Life Balance and Work Stress during the COVID-19 Pandemic in Indonesia. Economies, 9, 96.

https://doi.org/10.3390/economies9030096

Langemeier, M. (2018). Labor Efficiency and Productivity Benchmarks. Journal of ASFMRA, 17-28.

McKinsey. (2020). Accelerating your digital transformation. https://www.mckinsey.com/ /media/McKin sey/Email/Classics/2020/2020-

10classic.html

Megits, N., Neskorodieva, I., \& Schuster, J. (2020). Impact assessment of the COVID-19 on trade between Eastern Europe and China. Journal of Eastern European and Central Asian Research (JEECAR), 7(3), 385-399. https://doi.org/10.15549/jeecar.v7i3.579

Menke, W. (2018). Factor Analysis. Geophysical Data Analysis (Fourth Edition). New York: Academic Press, 207-222.

Microsoft. (2020). The Next Great Disruption Is Hybrid Work - Are We Ready? https://www.microsoft.com/enus/worklab/work-trend-index/hybrid-work

Miglioretti, M., Gragnano, A., Margheritti, S., \& Picco, E. (2021). Not All Telework is Valuable. Journal of Work and Organizational Psychology, 37(1), 11-19. https://doi.org/10.5093/jwop2021a6

Nilles, J. M. (1975). Telecommunications and organizational decentralization. IEEE Transactions On Communications, 11421147.

Nilles, J. M. (1994). Making telecommuting happen: a guide for telemanagers and telecommuters. New York: Van Nostrand Reinhold.

Nuwer, R. (2016). No Workplace Like Home. Scientific American Mind, 27(5), 38-43.
Owl Labs, Global Workplace Analytics. (2019). State of Remote Work. https://www.owllabs.com/state-of-remotework/2019

Pirtskhalaishvili, D., Paresashvili, N., \& Kulinich, T. (2021). The gender aspects of career development and leadership in organizations. Journal of Eastern European and Central Asian Research (JEECAR), 8(2), 255 - 266. https://doi.org/10.15549/jeecar.v8i2.654

Schall, M.A. (2019). The Relationship Between Remote Work and Job Satisfaction: The Mediating Roles of Perceived Autonomy, Work-Family Conflict, and Telecommuting Intensity. San Jose State University. https://doi.org/10.31979/etd.2x82-58pg

Taherdoost, H. (2017). Determining Sample Size; How to Calculate Survey Sample Size. International Journal of Economics and Management Systems, 2, 237-239.

Van Zoonen, W., Sivunen, A., Blomqvist, K., Olsson, T., Ropponen, A., Henttonen, K., \& Vartiainen, M. (2021). Factors Influencing Adjustment to Remote Work: Employees' Initial Responses to the COVID-19 Pandemic. International Journal of Environmental Research and Public Health, 18(13), 6966. https://doi.org/10.3390/ijerph18136966

Vasiljeva, M., Neskorodieva, I., Ponkratov, V., Kuznetsov, N., Ivlev, V., Ivleva, M., Maramygin, M., \& Zekiy, A. (2020). A Predictive Model for Assessing the Impact of the COVID-19 Pandemic on the Economies of Some Eastern European Countries. Journal of Open Innovation: Technology, Market, and Complexity, 6(3), 92. https://doi.org/10.3390/joitmc6030092

Villani, V., Sabattini, L., Żołnierczyk-Zreda, D., Mockałło, Z., Barańska, P., \& Fantuzzi, C. (2021). Worker satisfaction with adaptive automation and working conditions: a theoretical model and questionnaire as an assessment tool. International Journal of Occupational Safety and Ergonomics. https://doi.org/10.1080/10803548.2021.189 9649

Wang, B., Liu, Y., Qian, J., \& Parker, S. (2021). Achieving Effective Remote Working During the COVID-19 Pandemic: A Work Design 
Perspective. Applied Psychology, 70, 16-59. https://doi.org/10.1111/apps.12290.

\section{ABOUT THE AUTHORS}

Eka Maghlaperidze, email: emaghlaperidze@gmail.com

Eka Maghlaperidze is a Ph.D. student at Ivane Javakhishvili Tbilisi State University (TSU), majoring in Management and currently working on a Ph.D. thesis about the Remote Working; Ph.D. in Business Administration (Faculty of Economics and Business). She completed a Masters' Degree with Honours in Management from TSU (2018) and the Bachelor's degree in International Business from Ostfold University College, Norway (2016). She is working as a Head of Marketing at one of the biggest distribution companies in Georgia, marketing some of the famous international brands in collaboration with the international partners. Her main research interests are human resource management, marketing management and organizational development.

Natalia Kharadze has a Ph.D. in Economics, an Associate Professor at Ivane Javakhishvili Tbilisi State University (TSU). She is the Founder \& CEO of the Human Resource Management Laboratory, which aims to conduct research in this field. She is an author of more than 80 scientific publications and two monographs, with citation index - 221, H-index - 9, and G-index - 9. She is a member of the editorial \& International Scientific Advisory Board of the European Journal of Economics and Business Studies. Her main research interests include human resource management, leadership, career management, and time management issues.

Halyna Kuspliak has a Ph.D. in Public Administration. She is the Associate Professor of the Regional Policy and Public Administration Department, Odesa Regional Institute for Public Administration of the National Academy for Public Administration under the President of Ukraine. 